\title{
Corrosion Processes in the Concrete of the Dams
}

\author{
Mark A. Sadovich, Tatyana F. Shlyakhtina and Anna M. Kuritsyna \\ Department of Technology, Bratsk State University, Bratsk 665709, Russia
}

\begin{abstract}
During the whole operation life of Bratsk and Ust-Ilimsk hydroelectric plants, chemical analysis of water filtering through the pressure front of the concrete dams was under systematic monitoring by sampling in places of concentrated outcome in the inspection galleries of a dam. Long-term cumulative observations made up a basis for study of the indicated dams concrete corrosion caused by the Angara water in the process of its filtration through the cracks formed in the period of the dam erection, through construction joints and other defects. Mathematical-statistical analysis allowed the classification the processes of corrosion from the point of view of their time dynamics and divided them correspondingly into stationary (stable) and non-stationary. On the basis of a calculation of the cement stone component removal along with the ideas of the process dynamics the pressure front filtration development forecast has been made and their danger level has been estimated. The developed conception is of rather a general character and can be used when analyzing the state of concrete dams of the Angara cascade and other similar cases.
\end{abstract}

Key words: Concrete corrosion, concrete endurance, water filtration, filtration seepage, dam, pressure front, leaching, component removal.

\section{Introduction}

Eastern Siberia is one of the major suppliers of electric power in the United Power Grid of Russia. At the same time fair amount of electricity is generated by hydropower plants of the Angara cascade. Under these conditions performance reliability of hydropower plant concrete dam exposed to the effect of the Angara waters is of special significance.

It is obvious that the interest to the reliability of concrete dams will steadily rise in proportion to aging and change of service conditions forming under the influence of constantly varying environment. In full measure it refers to high concrete dams of Bratsk and Ust-Ilimsk hydro electric plants on the Angara River that have been running for more than 30 years.

Concrete endurance in water medium is one of the major longevity problems of concrete hydraulic structures. Depending on real dam running conditions, the effect of filtrated water on the concrete can have a destructive pattern that becomes apparent in the increase of seepage and, as an after-effect, in the

Corresponding author: Mark A. Sadovich, D.Sc., professor, research field: durability monolithic concrete constructions. E-mail: kaftsp@brstu.ru. reliability degradation of the construction. The process of corrosion running in the body of dam can lead to serious damages of the pressure front that will entail in huge economic outlay for its reconditioning. In this connection the state of concrete of sustained operation constructions requires strict and skilled supervision.

The conception of concrete corrosion process of Bratsk and Ust-Ilimsk dams was developed on the basis of quality and quantity analysis of the cement stone basic components removal depending on the amount of filtration seepage which in its part was considered as one of the main parameters of the process.

\section{Analysis of Aggressiveness of the Angara Water towards Concrete}

Aggressive water attack is understood as its ability to destroy different building materials by acting upon them with dissolved salts and gases or washing away their component parts. The aggressive water attack on concrete constructions, particularly the Angara dams, permanent and potentially hazardous structures under heavy water head gain specific importance.

Evaluation research of water chemistry of Bratsk 
and Ust-Ilimsk reservoirs conducted by the Chemistry Laboratory of Ust-Ilimsk HPP in 1977-1999 and Hydrochemistry Laboratory of Irkutsk State University in 1977-1998 allowed to form notions on the water chemistry of the indicated reservoirs.

Long-term data analysis of water chemistry of the Angara artificial reservoirs showed that predominant anion is ion $\mathrm{HCO}_{3}^{-}$(its water content is $70-160 \mathrm{mg} / \mathrm{L}$ ) and the predominant cation is $\mathrm{Ca}^{2+}$ (its water content is $15-30 \mathrm{mg} / \mathrm{L}$ ). General water mineralization of all high Angara River reservoirs does not exceed 250 $\mathrm{mg} / \mathrm{L}$. Free $\mathrm{CO}_{2}$ content in reservoir water varies within the limits from $2.5 \mathrm{mg} / \mathrm{L}$ in summer time to 22 $\mathrm{mg} / \mathrm{L}$ in winter period of the year. According to hydrogen index $\mathrm{pH}$, Bratsk and Ust-Ilimsk reservoir waters are alkaline, however, gradual decline of $\mathrm{pH}$ from 8.8 to 7.7 is being observed during the whole observation period.

Water aggressiveness towards concrete is estimated according to a number of indices (Table 1).

Correlation of the Angara cascade reservoir water chemistry with the reduced criteria of non-aggressiveness shows that combination of leaching and carbon dioxide corrosion can take place in the dam concrete.

\section{Analysis of Full Scale Test Results}

In the process of condition control of the concrete pressure front of Bratsk and Ust-Ilimsk dams the sampling of water filtrated through the concrete in seepage sites of inspection galleries was carried out (Fig. 1).

Filtrate sampling methods met the following requirements: sampling time and site registration, sampling, storing and handling were to eliminate changes in the content of the defined components.

In compliance with universally recognized concepts leaching corrosion of cement stone is connected with dissolution and removal of main structure forming component, which provides concrete high strength characteristics and environment alkalinity necessary for steady existence of cement stone minerals [1-3].

Actually, at the filtration chemistry analysis the ions of calcium was discovered not to be removed but precipitate in the process of concrete filtration approximately in the half of the survey cases, i.e., calcium ion concentration in the filtrate is lower than in the reservoir water [4]. Simultaneously an abrupt increase of sodium and potassium ions concentration is observed in comparison with the reservoir water (Fig. 2).

The presence of removal of the mentioned compounds from the concrete depends on the filtration seepage. At minor seepage (up to $0.005 \mathrm{~L} / \mathrm{min}$ ) there is a decrease of ions $\mathrm{Ca}^{2+}$ content in comparison with the reservoir (precipitation). Here an abrupt increase of ions $\mathrm{N}^{+}$and $\mathrm{K}^{+}$content and corresponding decrease of free $\mathrm{CO}_{2}$ up to its complete absence in the filtrate is marked. At seepage rates in the interval from 0.005 $\mathrm{L} / \mathrm{min}$ to $0.02 \mathrm{~L} / \mathrm{min}$ both precipitation and removal of calcium ions are observed. At higher seepage rates (over $0.02 \mathrm{~L} / \mathrm{min}$ ) the removal of ions $\mathrm{Ca}^{2+}$ and $\mathrm{Na}^{+}$, $\mathrm{K}^{+}$takes place.

The calculation of removed substances testifies that sodium rather than calcium prevail compounds in the filtrate (Table 2).

Phenomenon of predominant removal of sodium compounds from the concrete is not a fact of common language. Nevertheless, it is quite explicable. To build a pressure front of Bratsk and Ust-Ilimsk dams

Table 1 Indices of non-aggressiveness and corresponding content of aggressive components in the water of the Angara River.

\begin{tabular}{lll}
\hline \multirow{2}{*}{ Index of aggressiveness } & \multicolumn{3}{l}{ Index of non-aggressiveness of flow Content in the water of the Angara } \\
& medium for pressure structures & River \\
\hline Bicarbonate hardness $(\mathrm{mg} / \mathrm{L})$ & Over 64.05 & $64.1 \div 122.0$ \\
Hydrogen index $(\mathrm{pH})$ & Over 5 & 7.5 \\
Content of aggressive carbon dioxide $(\mathrm{mg} / \mathrm{L})$ & Less than 10 & $4.0 \div 12.0$ \\
Summary content of chlorides, sulfates, nitrates $(\mathrm{g} / \mathrm{L})$ & Less than 10 & $20 \mathrm{mg} / \mathrm{L}$ \\
\hline
\end{tabular}




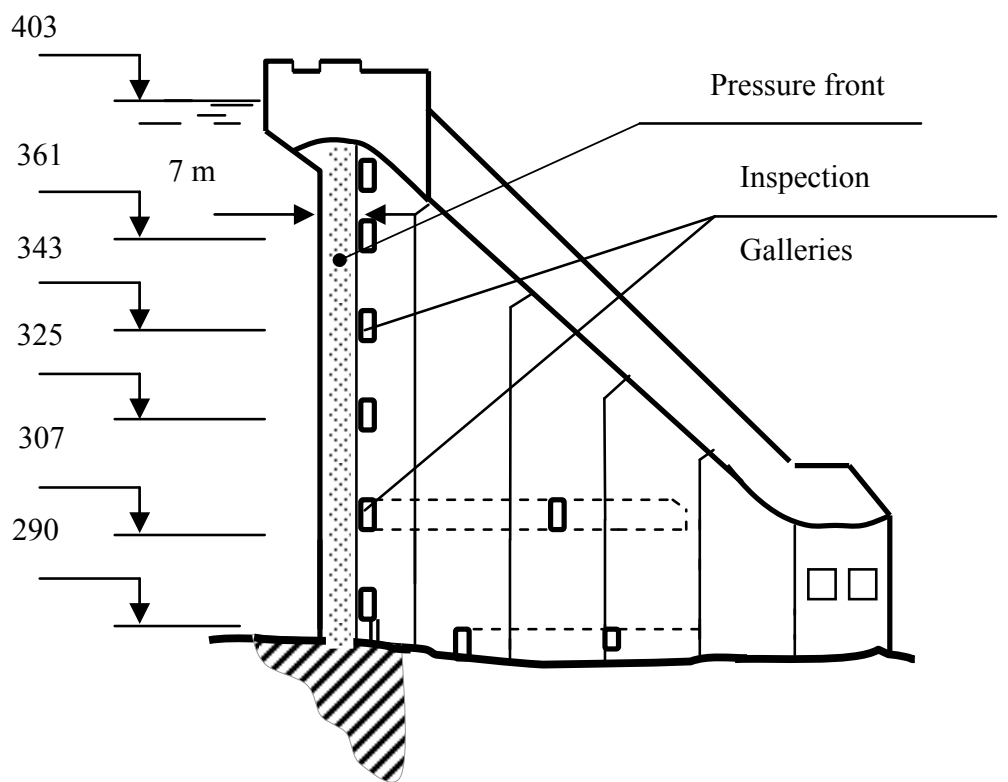

Fig. 1 Cross section of a gravitation dam.

Portland slag cement of Krasnoyarsk plant was used. It contains up to $50 \%$ of Magnitogorsk blust-furnace slag. The cement content of alkaline oxides $\mathrm{Na}_{2} \mathrm{O}+$ $\mathrm{K}_{2} \mathrm{O}$ is defined by their presence in clinker (up to $1 \%$ ) and in mineral additives. From literature sources it is known that there are about $2 \%$ of sodium and potassium oxides in Magnitogorsk slag. Hence, at the content of alkaline oxides in cement up to $50 \%$ of blast-furnace slag, the content of alkaline oxides in cement makes up $1-1.5 \%$. Since sodium and potassium oxides are chemically more active than calcium hydroxide, the process of their dilution in the water filtrated is imposed on the general pattern of cement stone corrosion.

It is important to note, that the degree of saturation of the filtrate with ions of sodium and potassium and corresponding rise of filtrate alkalinity depend on filtration rate. So, at filtration rates up to $0.02 \mathrm{~L} / \mathrm{min}$ filtrate $\mathrm{pH}$ rises to $10-12$ in comparison with 7-8 in the reservoir. At higher rate this abrupt rise of alkalinity is not marked.

As it has already been noted, the Angara water can be a source of carbon-dioxide corrosion due to presence of aggressive carbonic acid (Table 1). It is necessary to point out that recently there is a trend towards rise of water dissolved carbon dioxide content caused by biochemical processes and other factors exerting influence on the reservoir water chemistry.

Existence of pressure front concrete carbon dioxide corrosion is verified by the rise of concentration of carbonate ions $\mathrm{CO}_{3}{ }^{2-}$ and $\mathrm{HCO}_{3}{ }^{-}$in the filtrate in comparison with the reservoir water. Simultaneously an abrupt decrease of free $\mathrm{CO}_{2}$ is marked, up to its complete absence in the filtrate that confirms its conversion in carbonate compounds. The search of correlation links between ions $\mathrm{Ca}^{2+}$ and $\mathrm{Na}^{+}+\mathrm{K}^{+}$and carbonate ions allowed to find out the presence of a close correlation link only between the content of ions $\mathrm{Na}^{+}+\mathrm{K}^{+}$and carbonate $\mathrm{CO}_{3}{ }^{2-}$ in the filtrate (correlation coefficient is 0.91-0.95). In this connection, availability of calcium bicarbonate $\mathrm{Ca}\left(\mathrm{HCO}_{3}\right)_{2}$ becomes improbable. The process of carbon dioxide corrosion runs in such a way that first of all easily dissolved compounds of $\mathrm{Na}_{2} \mathrm{CO}_{3}$ and $\mathrm{NaHCO}_{3}$ type are formed. The pointed peculiarity allows to give explanation to such a phenomenon as calcium sedimentation on the ways of filtration. As far as formation of bicarbonate calcium in the reservoir water becomes possible only with availability of a definite amount of free $\mathrm{CO}_{2}$, its conversion into 

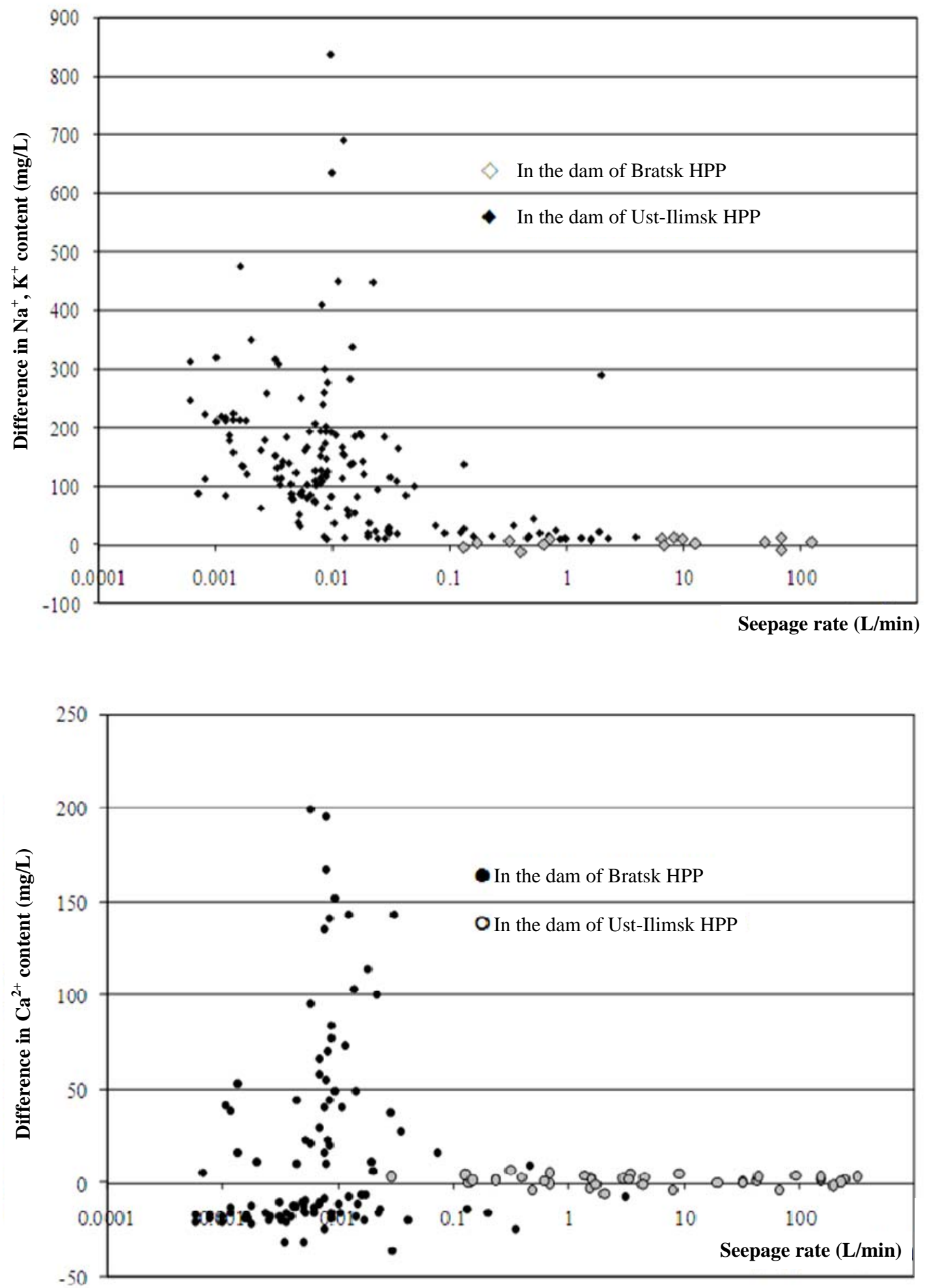

Fig. 2 Relation between the amount of filtration flow and the difference in ions $\mathrm{Ca}^{2+}$ and $\mathrm{Na}^{+}$content in the filtrate in comparison with reservoir water. 
Table 2 Average values of annual amount of dam concrete components removed precipitated by filtrated water counting on $\mathrm{CaO}$ and $\mathrm{Na}_{2} \mathrm{O}$.

\begin{tabular}{|c|c|c|c|c|}
\hline \multirow{2}{*}{\multicolumn{3}{|c|}{ Site of sampling }} & \multicolumn{2}{|c|}{ Average annual removal (kg/year) } \\
\hline & & & \multirow{2}{*}{$\begin{array}{l}\mathrm{CaO} \\
+0.529\end{array}$} & \multirow{2}{*}{$\frac{\mathrm{Na}_{2} \mathrm{O}}{+6.15}$} \\
\hline Mark 307 & section 40 & drain 5 & & \\
\hline Mark 307 & s 46 & d 5 & +1.29 & +0.468 \\
\hline Mark 307 & s 55 & $\mathrm{~d} 4 \mathrm{a}$ & +0.72 & +1.26 \\
\hline Mark 307 & s 59 & d $6 a$ & -0.04 & +0.46 \\
\hline Mark 325 & s 36 & d 3 & $\mathrm{n} / \mathrm{o}$ & +15.73 \\
\hline Mark 325 & s 39 & $\mathrm{~d} 4 \mathrm{a}$ & $\mathrm{n} / \mathrm{o}$ & +12.46 \\
\hline Mark 325 & s 41 & $\mathrm{~d} 4$ & +3.393 & +7.52 \\
\hline Mark 325 & s 45 & d 5 & +0.323 & +1.99 \\
\hline Mark 343 & s 31 & d 5 & +1.107 & +2.26 \\
\hline Mark 343 & s 34 & d 3 & -0.12 & +0.58 \\
\hline Mark 343 & s 35 & d 5 & +0.13 & +0.432 \\
\hline Mark 343 & s 37 & d 5 & -0.05 & +0.4 \\
\hline Mark 343 & s 39 & d 6 & +0.07 & +0.398 \\
\hline Mark 343 & s 54 & d 4 & -0.066 & +0.52 \\
\hline Mark 361 & s 52 & $\mathrm{~d} 4$ & -0.011 & +6.6 \\
\hline Mark 361 & s 58 & d 5 & +0.157 & +2.43 \\
\hline Mark 361 & s 60 & $\mathrm{~d} 2$ & -0.153 & +1.21 \\
\hline Mark 361 & s 61 & d 5 & -0.342 & +3.0 \\
\hline Mark 361 & s 63 & $\mathrm{~d} 4$ & -0.024 & +0.34 \\
\hline
\end{tabular}

$\mathrm{n} / \mathrm{o}$ - not observed due to minor difference in ion concentration in the filtrate in comparison with the reservoir water; + is removal of components with a filtrate; - is precipitation of components on ways of filtration.

carbonate compounds $\mathrm{Na}$ and $\mathrm{K}$ distorts this natural balance and the reaction runs towards decomposition of a bicarbonate into a precipitating carbonate and carbon acid. Decomposition of a bicarbonate releases new portion of carbon dioxide which is able to converse into carbonate compounds of sodium and potassium.

$$
\mathrm{Ca}\left(\mathrm{HCO}_{3}\right)_{2} \leftrightarrows \mathrm{CaCO}_{3}+\mathrm{CO}_{2}+\mathrm{H}_{2} \mathrm{O}
$$

Low soluble $\mathrm{CaCO}_{3}$ is precipitated on the filtration ways or is water removed on the surface of the concrete where it precipitates as saline sediments. This is supported by chemical analysis of saline sediments that showed that $\mathrm{CaCO}_{3}$ makes up $93 \%$ of their content.

However, the impact of carbonate compounds of $\mathrm{Na}$ and $\mathrm{K}$ is not limited by decomposition of bicarbonate calcium. Emergence of new carbonate compounds $\mathrm{Na}^{+}$and $\mathrm{K}^{+}$in the filtrate sufficiently increases its hardness in comparison with reservoir water which inevitably results in the decrease of solubility of
$\mathrm{Ca}(\mathrm{OH})_{2}$ in the cement stone, i.e., attenuation process of lime leaching can take place.

The suggested pattern of a corrosion process considering the effect of sodium and potassium oxides can not be regarded ignoring the filtration seepage, the amount of which defines the degree of saturation of the filtrate by the products of corrosion. Precipitation of $\mathrm{CaCO}_{3}$ is possible only at sufficient saturation of the filtrate by carbonate compounds of sodium and potassium that occurs to a different degree by filtration rates up to $0.02 \mathrm{~L} / \mathrm{min}$.

Further increase of filtration seepage and corresponding fall of concentration of the soluble components of the cement stone changes the pattern of the corrosion process in such a way that dissolution and removal of both alkaline oxides and calcium hydrocarbonate are determined only by the diffusion of the mentioned compounds from concrete. At discharges of more than $0.5 \mathrm{~L} / \mathrm{min}$ the addition of concentration of the controlled ions in the filtrate in 
comparison with the reservoir water is so small that it creates illusion for absence of corrosion. It is evident that these most dangerous sites of filtration in the dam require a more accurate monitoring for the ion concentration both in the filtrate and in the reservoir water so that the true pattern of the corrosion process would not elude the researcher.

Thus, the suggested pattern of a corrosion process in concrete affected by the water under study takes into account the effect of the cement present easy soluble sodium and potassium alkali and describes the state of the processes depending on filtration processes that in their turn determine the concentration of soluble compounds in the filtrate. The stated approaches allow to explain such a little known phenomenon as decrease of calcium ion concentration in the filtrate in comparison with reservoir water.

An important characteristic of concrete condition on the ways of filtration is the time dynamics of filtration seepage. It carried out analysis of change of measured filtration discharges presented as time series allowed to evolve filtration sites that are specified by the stationary process state with a trend towards attenuation and the sites with relatively large outlay in the form of non-stationary process without any trend towards attenuation. Principal dependencies of amount of the cement stone removed components on the observable filtration discharges were discovered.

At filtration rates up to $0.005 \mathrm{~L} / \mathrm{min}$ the process of cement stone removal from the concrete has a stationary attenuating pattern, and the removal amount at separate inspection sites does not exceed $1 \mathrm{~kg} /$ year.

At filtration rates from $0.005 \mathrm{~L} / \mathrm{min}$ to $0.02 \mathrm{~L} / \mathrm{min}$ the process of attenuation is mainly stationary, in some cases with a pronounced trend towards attenuation. The removal of the cement stone components is up to $6 \mathrm{~kg} /$ year.

At filtration rates over $0.02 \mathrm{~L} / \mathrm{min}$ the process, as a rule, is non-stationary with peaks in separate years at some inspection sites equal to $30 \mathrm{~kg} / \mathrm{year}$.

\section{Experimental Verification of $\mathrm{Na}$ and $\mathrm{K}$ Oxides Effect}

To verify the proposed assumptions on the effect of diffusion of alkaline ions $\mathrm{Na}^{+}$and $\mathrm{K}^{+}$on the state of bicarbonate in the reservoir water and free $\mathrm{CO}_{2}$ an experiment aimed at simulation of processes running in the concrete filtrated water at small filtration seepage was conducted. The essence of the experiment was in stepwise saturation of the reservoir water of known composition with ions of sodium and monitoring for the quantity content of calcium ions and free $\mathrm{CO}_{2}$ in the solution. To this end, five samples of reservoir water of $300 \mathrm{mg}$ each were taken and after water chemistry analysis the alkali $\mathrm{NaOH}$ of 0.1 gram-molecule/L concentration in volumes $15,30,45$, 60 and $90 \mathrm{~mL}$ was added. The data on the content of sodium and potassium ions determined after $6 \mathrm{~h}$ of aging are given in Table 3 .

It shows that increase of concentration of sodium ions is accompanied by the fall of calcium ions content in comparison with water reservoir that corresponds to settling-out in the form of $\mathrm{CaCO}_{3}$. At this stage the reaction most likely runs according to the scheme:

$$
\begin{gathered}
\mathrm{Ca}^{2+}+2 \mathrm{HCO}_{3}{ }^{-}+2 \mathrm{Na}^{+}+2 \mathrm{OH}^{-} \Rightarrow \mathrm{CaCO}_{3} \downarrow+ \\
2 \mathrm{Na}^{+}+\mathrm{CO}_{3}{ }^{2-}+2 \mathrm{H}_{2} \mathrm{O}
\end{gathered}
$$

Availability of free $\mathrm{CO}_{2}$ in the solution after adding of $\mathrm{NaOH}$ is not discovered.

The second part of the experiment was verification of the assumption that saturation of the filtrate with sodium compounds affects the lime solubility.

A hanging of $\mathrm{Ca}(\mathrm{OH})_{2}$ weighing $50 \mathrm{mg}$ (Table 3) was put into each of five samples and in reservoir water. Determination of calcium ions content in the solution $2 \mathrm{~h}$ after introduction of the lime carbonate showed that in pure reservoir water a part of $\mathrm{Ca}(\mathrm{OH})_{2}$ has dissolved (increment of $\mathrm{Ca}^{2+}$ concentration took place), whereas in samples saturated with sodium ions the lime carbonate not only remained insoluble but its availability in the solution contributed to further settling-out of $\mathrm{CaCO}_{3}$ (decrease of $\mathrm{Ca}^{2+}$ content). 
Table 3 The results of experimental verification of $\mathrm{Na}$ and $\mathrm{K}$ oxides effect.

\begin{tabular}{|c|c|c|c|c|c|c|c|c|c|c|c|}
\hline \multirow[t]{2}{*}{$\begin{array}{l}\text { No. } \\
\text { sam } \\
\text { ple }\end{array}$} & \multirow{2}{*}{$\mathrm{pH}$} & \multicolumn{2}{|c|}{$\begin{array}{l}\text { Ion content in } \\
\text { reservoir water, } \\
(\mathrm{mg} / \mathrm{L})\end{array}$} & \multirow{2}{*}{$\begin{array}{l}\text { Volume of added } \\
\text { alkali } \mathrm{NaOH} \text { per } \\
300 \mathrm{~mL} \text { of water } \\
(\mathrm{mL})\end{array}$} & \multicolumn{2}{|c|}{$\begin{array}{l}\text { Ion concentration } \\
\text { after adding } \\
\text { alkali }(\mathrm{mg} / \mathrm{L})\end{array}$} & \multirow{2}{*}{$\begin{array}{l}\mathrm{pH} \text { after } \\
\text { adding } \\
-\mathrm{NaOH}\end{array}$} & \multirow{2}{*}{$\begin{array}{l}\mathrm{CO}_{2} \text { free } \\
\text { content } \\
(\mathrm{mg} / \mathrm{L})\end{array}$} & \multirow{2}{*}{$\begin{array}{l}\text { Additive } \\
\mathrm{Ca}(\mathrm{OH})_{2} \text { per } \\
200 \mathrm{~mL} \text { of } \\
\text { solution }(\mathrm{mg})\end{array}$} & \multirow[t]{2}{*}{$\begin{array}{l}\text { Concentration } \\
\mathrm{Ca}^{2+}(\mathrm{mg} / \mathrm{L})\end{array}$} & \multirow[t]{2}{*}{ Appearance } \\
\hline & & $\mathrm{Ca}^{2+}$ & $\mathrm{Na}^{+}$ & & $\mathrm{Ca}^{2+}$ & $\mathrm{Na}^{+}$ & & & & & \\
\hline 1 & \multirow{6}{*}{7.5} & \multirow{6}{*}{50.1} & \multirow{6}{*}{7.98} & 15 & 43.2 & 211.6 & 9.6 & \multirow{5}{*}{$\begin{array}{l}\text { Is not } \\
\text { discovere } \\
\text { d }\end{array}$} & \multirow{5}{*}{50} & 21.6 & \multirow{6}{*}{$\begin{array}{l}\text { Turbid } \\
\text { whitish } \\
\text { solution, after } \\
\text { settling has a } \\
\text { flocculent } \\
\text { white } \\
\text { sediment } \\
\text { Clear solution }\end{array}$} \\
\hline 2 & & & & 30 & 40.08 & 340.7 & 9.76 & & & 19.04 & \\
\hline 3 & & & & 45 & 36.2 & 452.3 & 9.8 & & & 18.5 & \\
\hline 4 & & & & 60 & 30.06 & 591.8 & 9.9 & & & 17.03 & \\
\hline 5 & & & & 90 & 25.5 & 855.9 & 9.96 & & & 13.1 & \\
\hline 6 & & & & 0 & 50.1 & 7.98 & 7.5 & 7.7 & 50 & 157.3 & \\
\hline
\end{tabular}

At this stage the following reactions can take place, each provoking the settling-out of $\mathrm{CaCO}_{3}$.

$$
\begin{aligned}
\mathrm{Ca}^{2+}+2 \mathrm{HCO}_{3}{ }^{-} & +\mathrm{Ca}^{2+}+2 \mathrm{OH}^{-} \Rightarrow 2 \mathrm{CaCO}_{3} \downarrow \\
& +2 \mathrm{H}_{2} \mathrm{O} \\
2 \mathrm{Na}^{+}+\mathrm{CO}_{3}{ }^{-}+ & \mathrm{Ca}^{2+}+2 \mathrm{OH}^{-} \Rightarrow \mathrm{CaCO}_{3} \downarrow \\
& +2 \mathrm{Na}^{+}+\mathrm{OH}^{-} \\
2 \mathrm{Na}^{+}+2 \mathrm{HCO}_{3}{ }^{-}+\mathrm{Ca}^{2+}+2 \mathrm{OH}^{-} \Rightarrow \mathrm{CaCO}_{3} \downarrow & +2 \mathrm{Na}^{+}+\mathrm{CO}_{3}{ }^{2-}+2 \mathrm{H}_{2} \mathrm{O}
\end{aligned}
$$

The experiment has confirmed the stated assumptions about the effect of diffusion of alkaline ions $\mathrm{Na}^{+}$and $\mathrm{K}^{+}$on the state of bicarbonate in the reservoir water, free $\mathrm{CO}_{2}$ and lime carbonate under conditions corresponding to small filtration discharges.

\section{Conclusions}

The evaluation of the concrete state of dam pressure front over more than 30 years of operation allows to ascertain the availability of set ways of filtration. Some of them are characterized by a trend toward attenuation of filtration seepage and the other keep a non-stationary status and pose a definite threat of development. The sites of emergence of filtration are timed to crack and vertical drains and so most liable filtration lines go along vertical cracks of the concrete body and the horizontal construction joints through which drains can also be injected. Due to absence of particular data on filtration ways and corresponding area of concrete surface washed by water, the evaluation of filtration effect on the concrete status remains to be conducted according to comparative characteristics for evidently safe and relatively adverse sites of filtration.

On the whole over the period of the dam operation cement stone components removal at specifically inspected sites counting on $\mathrm{Na}_{2} \mathrm{O}$ makes up $30-50 \mathrm{~kg}$ and at some sites it is up to $100 \mathrm{~kg}$. The removal of $\mathrm{CaO}$ is significantly less, up to $30 \mathrm{~kg}$. For the concrete of the pressure front that has hardened for some years the content of $\mathrm{Ca}(\mathrm{OH})_{2}$ makes up $15-20 \mathrm{~kg} / \mathrm{m}^{3}$ or respectively $1: 1,5 \%$ of the cement body which conforms to $2-3 \mathrm{~kg} / \mathrm{m}^{3}$ (with slag Portland cement discharge of $230 \mathrm{~kg} / \mathrm{m}^{3}$ of concrete). To remove the stated amount of $\mathrm{Na}_{2} \mathrm{O}$ with the filtrate it is necessary for the process of leaching to span $10-20 \mathrm{~m}^{3}$ of concrete but as long as the solution starts from the surface washed by the filtrated water one could assume that this surface makes up $100-200 \mathrm{~m}^{3}$ with an active zone depth of $10 \mathrm{~cm}$ which is completely real. At that, rather a big supply of $\mathrm{Ca}(\mathrm{OH})_{2}$ still remains in the concrete.

In spite of the fact that the removal of $\mathrm{Na}_{2} \mathrm{O}$ is not dangerous for the concrete the nature of the phenomena stated is destructive since it contributes to the development of capillary porosity of the cement stone and the fall of $\mathrm{pH}$ environment.

At the same time there are seepages of filtration water at which the calculated amount of the cement stone components removed with a filtrate is significantly higher than the above analyzed. At some sites the removal makes up $15 \mathrm{~kg} /$ year and over without any trend toward the fall of filtration seepage. 
From the point of view of concrete state such filtration sites are most dangerous as the removal over the whole period of operation is estimated in hundreds of kilograms.

One could assume that the concrete contacting the filtration flow has already lost rather a tangible amount of $\mathrm{Ca}(\mathrm{OH})_{2}$ and the diffusion of $\mathrm{Na}_{2} \mathrm{O}$ and $\mathrm{K}_{2} \mathrm{O}$ comes out of the depth layers of concrete.

Thus, as a result of the analyses of the available data on the filtration in the concrete of the Angara dams pressure front both comparatively safe and most adverse sections were discovered. Their state monitoring is to be specified and continued.

\section{References}

[1] V.M. Moskvin, F.M. Ivanov, S.N. Alexeev, A. Guzeev, Corrosion of Concrete and Reinforced Concrete, Methods of Their Protection, Vol. 536, Stroiizdat, Moscow, 1980, pp. 113-123.

[2] S.N. Alexeev, F.M. Ivanov, N. Modry, P. Schiessel, Longevity of Reinforced Concrete in Corrosive Media, Vol. 320, Stroiizdat, Moscow, 1990, pp. 292-295.

[3] V.V. Kind, Corrosion of Cements and Concrete in Hydraulic Structures, Vol. 190, Cosenegroizdat, Moscow, 1955, pp. 135-140.

[4] M.A. Sadovich, T.F. Shlyakhtina, Z.I. Solov'yova, Peculiarities of corrosion process of Bratsk HPP concrete dam pressure front, Hydraulic Engineering Construction 3 (2000) 14-17. 